\title{
Levodopa therapy for Parkinsonism in the Shy-Drager syndrome
}

\author{
M. J. AMINOFF ${ }^{1}$, C. S. WILCOX, M. M. WOAKES, AND M. KREMER \\ From the Department of Neurological Studies, Middlesex Hospital Medical School, London
}

SUMmaRY The results of levodopa treatment in five patients with Parkinsonism of the Shy-Drager syndrome are reported. There was no improvement in the neurological signs or functional disability in any patient. Mean values for lying and standing blood pressure increased significantly in three of the five patients during treatment, and were unchanged in the other two patients. The significance of these results is discussed. It is concluded that levodopa is not of therapeutic value in patients with this disorder.

Patients with Parkinson's disease (Yahr, Duvoisin, Hoehn, Schear, and Barrett, 1968; Cotzias, Papavasiliou, and Schwartz, 1969; Godwin-Austen, Tomlinson Frears, and Kok, 1969) and with post-encephalitic Parkinsonism (Calne, Stern, Laurence, Sharkey, and Armitage, 1969) have recently been shown to benefit from levodopa therapy. Parkinsonism due to manganese intoxication also improves with levodopa (Mena, Court, Fuenzalida, Papavasilou, and Cotzias, 1970). Its value in patients with the Parkinsonism of the Shy-Drager syndrome has not, however, been established. Klawans and Zeitlin (1971) reported two patients with probable olivopontocerebellar atrophy who responded favourably and this encouraged us to assess its effect in the related Shy-Drager syndrome.

The Shy-Drager syndrome is a multi-system motor degenerative disorder of the central nervous system associated with orthostatic hypotension and other evidence of autonomic dysfunction (Shy and Drager, 1960). The somatic neurological manifestations include signs of pyramidal, extrapyramidal, cerebellar and lower motor neurone involvement. The most conspicuous and disabling feature is, however, a Parkinsonian syndrome that fails completely to respond to conventional anticholinergic drugs (Thomas and Schirger, 1970). It seemed important to us, therefore, to assess the therapeutic 1 Correspondence: Dr. M. J. Aminoff, Maida Vale Hospital, Maida
Vale, London W9 1TL. value of levodopa in patients with this severely disabling condition.

\section{METHODS}

Two male and three female patients with an average $\frac{\mathbb{D}}{2}$ age of 60 years were studied in hospital. All showeet the clinical features of Parkinsonism, with prominens bradykinesia. They had also pyramidal tract sign and these were associated with cerebellar signs i⿺ two patients and lower motor neurone signs in three? All of the patients had symptoms suggestive of postural hypotension. Urinary incontinence was troublesome in all, as was sexual impotence in the two male patients. Details of the methods used to investigate autonomic function are reported elsewhere (Aminoff and Wilcox, 1971). All patients had impaired cardiovascular reflex activity, with marked postural hypotension, and a disturbance of pilo. motor, sudomotor and bladder function. In addition, in the four who were infused with noradrenaline, there was a markedly supersensitive pressor response.

On admission to hospital, all patients were assessed independently by two of us. Levodopa therapy was withheld for the first week of their stay in hospital, during which they received intensive physiotherapy and were then reassessed. Levodopa therapy was cautiously introduced, commencing with a daily dose of $250 \mathrm{mg}$ which subsequently increased by $500 \mathrm{mg}$ increments at approximately weekly intervals until they were receiving maximum tolerated doses. They were reassessed at fortnightly intervals by two of us, one of whom was unaware of the treatment that the patients were receiving. A 
more complete neurological and functional assessment was also made by one of us before levodopa therapy and after the patients had received maximum tolerated doses for at least three weeks. This assessment was similar to that of Godwin-Austen et al. (1969) and was done on a standard proforma.

Patients' symptoms, signs, and functional capabilities were graded 0 (normal), 1 (mild), 2 (moderate), 3 (marked), 4 (unable to perform). The functional capacities which we assessed were the ability to feed, dress, wash, bathe, and write; to sit on and stand up from a chair; to get into and out of bed, and to turn over in bed.

The lying and standing blood pressure was recorded four times daily for all patients before and during levodopa therapy. During the period of study patients were continued on their previous antiParkinsonism drugs.

\section{RESULTS}

Four of the five patients were able to tolerate between 2.5 and $3.5 \mathrm{~g}$ levodopa daily. The remaining patient became increasingly confused, withdrawn, and bradykinetic on $1.25 \mathrm{~g}$ levodopa daily and treatment was, therefore, stopped. No

TABLE 1

RESPONSE TO LEVODOPA

\begin{tabular}{lccc}
\hline $\begin{array}{l}\text { Individual features } \\
\text { assessed }\end{array}$ & \multicolumn{3}{c}{ Number of patients } \\
\cline { 2 - 4 } & Improved & Unchanged & Worsened \\
\hline Functional capacity & 0 & 1 & 4 \\
Physical signs & & & \\
$\begin{array}{l}\text { Bradykinesia } \\
\text { Rigidity } \\
\text { Tremor }\end{array}$ & 0 & 2 & 3 \\
\hline
\end{tabular}

patient showed any favourable response to treatment. Four patients showed an increase in their neurological deficit and functional incapacity (Table 1) which was reversed by withdrawing the levodopa. There was a significant rise in the lying mean blood pressure of three patients and the standing mean pressure of two patients during levodopa therapy (Table 2).

\section{DISCUSSION}

Parkinsonism is usually the most disabling somatic feature of the Shy-Drager syndrome. It occurred in most of the patients reported by Thomas and Schirger (1970) and failed completely to respond to anticholinergic medication. The clinical features of our patients correspond closely with those previously reported in this syndrome (Shy and Drager, 1960; Thomas and Schirger, 1970), and Parkinsonism was prominent in all of them. In four of our five patients there was a definite increase in neurological deficit and functional disability on levodopa, which was reversed by withdrawing the drug.

The explanation for the failure of our patients to respond to levodopa therapy is uncertain, but it may relate to the neuropathology of the condition. In Parkinson's disease an anatomical locus of the disorder is now established. Prominent and consistent changes occur in the substantia nigra of patients with Parkinson's disease or post-encephalitic Parkinsonism (Klaue, 1940; Hassler, 1948; Adams, 1968) and are regarded as the characteristic pathology of these disorders (Greenfield, 1963). Degeneration of the nigrostriatal pathway occurs (Andén, Dahlström,

TABLE 2

EFFECT OF LEVODOPA THERAPY ON LYING AND STANDING BLOOD PRESSURE (mean \pm SE)

\begin{tabular}{|c|c|c|c|c|c|}
\hline & \multicolumn{5}{|c|}{ Cases } \\
\hline & 1 & 2 & 3 & 4 & 5 \\
\hline $\begin{array}{l}\text { Lying mean blood pressure }(\mathrm{mm} \mathrm{Hg}) \\
\text { 1. Before levodopa } \\
\text { 2. On levodopa (maximum tolerated dose) } \\
\text { Statistical significance of difference between } 1 \text { and } 2\end{array}$ & $\begin{array}{r}93 \cdot 8 \pm 3 \cdot 9 \\
102 \cdot 5 \pm 3 \cdot 0 \\
P<0.025\end{array}$ & $\begin{aligned} 93 \cdot 7 & \pm 2 \cdot 6 \\
104 \cdot 0 & \pm 4 \cdot 8 \\
P & <0.05\end{aligned}$ & $\begin{array}{r}96.4 \pm 1 \cdot 3 \\
103.0 \pm 1 \cdot 8 \\
P<0.0025\end{array}$ & $\begin{array}{c}105 \cdot 7 \pm 4 \cdot 0 \\
105 \cdot 0 \pm 3 \cdot 6 \\
\text { NS }\end{array}$ & $\begin{array}{c}88 \cdot 3 \pm 2 \cdot 7 \\
88 \cdot 5 \pm 4 \cdot 1 \\
\text { NS }\end{array}$ \\
\hline $\begin{array}{l}\text { Standing mean blood pressure }(\mathrm{mm} \mathrm{Hg}) \\
\text { 1. Before levodopa } \\
\text { 2. On levodopa (maximum tolerated dose) } \\
\text { Statistical significance of difference between } 1 \text { and } 2\end{array}$ & $\begin{array}{c}80 \cdot 4 \pm 6 \cdot 1 \\
79 \cdot 3 \pm 2 \cdot 6 \\
\text { NS }\end{array}$ & $\begin{array}{l}74.0 \pm 1.6 \\
79.7 \pm 3.3 \\
P<0.01\end{array}$ & $\begin{array}{r}87.5 \pm 2.9 \\
99.2 \pm 1.8 \\
P<0.0025\end{array}$ & $\begin{array}{l}95.1 \pm 3.3 \\
97.5 \pm 3.6 \\
P<0.025\end{array}$ & $\begin{array}{c}71 \cdot 5 \pm 2 \cdot 7 \\
71 \cdot 6 \pm 3 \cdot 1 \\
\text { NS }\end{array}$ \\
\hline
\end{tabular}


Fuxe, and Larsson, 1965) with a subsequent reduction in the concentration of dopamine in the basal ganglia (Hornykiewicz, 1966). Thus, experimental destruction of nigral cells in monkeys similarly leads to a reduction of striatal dopamine levels (Poirier and Sourkes, 1965). It has been suggested that dopamine is a neurotransmitter with an inhibitory influence on striatal neurones (McLennan and York, 1967) and Parkinsonism may represent an imbalance in the basal ganglia of excitatory cholinergic and inhibitory dopaminergic mechanisms (McGeer, Boulding, Gibson, and Foulkes, 1961 ; Barbeau, 1962; Galindo, Krnjević, and Schwartz, 1967). The supporting evidence for this hypothesis remains incomplete at the present time (Barbeau, 1969). Nevertheless, it provides a theoretical basis for levodopa therapy in Parkinsonismnamely, the restoration of an effective inhibitory influence on striatal neurones by raising the local concentration of dopamine (Barbeau, 1962; Hornykiewicz, 1966). It may be that striatal or pallidal lesions-rather than degeneration of nigrostriatal pathways-underlie the features of Parkinsonism in patients with the Shy-Drager syndrome and modify their response to treatment with levodopa and anticholinergic drugs (Klawans, Ilahi, and Shenker, 1970). This implies that Parkinsonism in this condition does not represent an imbalance of excitatory and inhibitory mechanisms in the basal ganglia. Certainly in these patients cell loss and gliosis have frequently been reported in the putamen and outer pallidum (Shy and Drager, 1960; Johnson, Lee, Oppenheimer, and Spalding, 1966; Nick, Contamin, Escourolle, Guillard, and Marcantoni, 1967; Schwarz, 1967) as well as in the substantia nigra and elsewhere. Furthermore, this would accord with the reported failure of levodopa therapy in two patients with striatonigral degeneration (Izumi, Inoue, Shirabe, Miyazaki, and Kuroiwa, 1971).

It is not known why some patients with classical Parkinson's disease fail to respond to levodopa therapy. It would be of some interest, therefore, to compare the response to levodopa with the neuropathological features at necropsy in a series of patients with Parkinson's disease.

Levodopa may cause orthostatic hypotension in patients with Parkinson's disease (Calne et al., 1970). We, therefore, introduced it cautiously, since all of our patients had severe pre-existing orthostatic hypotension. However, their blood pressure either increased or remained unchanged during levodopa therapy and the clinical deterioration of our patients cannot, therefore, be ascribed to an exacerbation of orthostatic hypotension. Recent experimental studies suggest an explanation for the pressor response to levodopa of patients with the Shy-Drager syndrome. Levodopa, after conversion in the body to dopamine, has a central depressor and peripheral pressor action (Henning and Rubenson, 1970; Watanabe, Chase, and Cardon, 1970). In the Shy-Drager syndrome there is functional interruption of sympathetic connections between brain and periphery that may be complete (Aminoff and Wilcox, 1971). In these patients, the central depressor action of levodopa will be lost, leaving unopposed its peripheral pressor action.

This pressor action of levodopa may well prove $\dot{\omega}_{\infty}$ useful in the treatment of patients who have idio $\omega$ pathic orthostatic hypotension, but no somatie्p neurological deficit. In patients with the Shy Drager syndrome, its use is clearly precluded bo the accompanying clinical deterioration.

\section{REFERENCES}

Adams, R. D. (1968). The striatonigral degenerations. In Handbook of Clinical Neurology, 6, 694-702. Edited by P. J. Vinken and G. W. Bruyn. North-Holland: Amsterdam.

Aminoff, M. J., and Wilcox, C. S. (1971). Assessment of autonomic function in patients with a Parkinsonian syndrome. British Medical Journal, 4, 80-84.

Andén, N.-E., Dahlström, A., Fuxe, K., and Larsson, K. (1965). Further evidence for the presence of nigroneostriatal dopamine neurons in the rat. American Journal of Anatomy, 116, 329-333.

Barbeau, A. (1962). The pathogenesis of Parkinson's disease: a new hypothesis. Canadian Medical Association Journal, 87, 802-807.

Barbeau, A. (1969). Parkinson's disease as a systemic dis- $\frac{\bar{\partial}}{0}$ order. In Third Symposium on Parkinson's Disease, pp. $\overline{-}$ 66-73. Edited by F. J. Gillingham, and I. M. L. Donaldson. Livingstone: Edinburgh.

Calne, D. B., Stern, G. M., Laurence, D. R., Sharkey, J., and Armitage, P. (1969). L-dopa in postencephalitic Parkinson- 3 ism. Lancet, 1, 744-747.

Calne, D. B., Brennan, J., Spiers, A. S. D., and Stern, G. M. 오ำ (1970). Hypotension caused by L-dopa. British Medical Journal, 1, 474-475.

Cotzias, G. C., Papavasiliou, P. S., and Gellene, R. (1969). Modification of Parkinsonism-chronic treatment with $\sigma$ L-dopa. New England Journal of Medicine, 280, 337-345.

Galindo, A., Krnjević, K., and Schwartz, S. (1967). Micro-O iontophoretic studies on neurones in the cuneate nucleus. $\mathbb{W}$ Journal of Physiology, 192, 359-377. 
Godwin-Austen, R. B., Tomlinson, E. B., Frears, C. C., and Kok, H. W. L. (1969). Effects of L-dopa in Parkinson's disease. Lancet, 2, 165-168.

Greenfield, J. G. (1963). System degeneration of the cerebellum, brain stem and spinal cord. In Greenfield's Neuropathology, 2nd edn., pp. 582-585. Edited by W. Blackwood, W. H. McMenemey, A. Meyer, R. M. Norman, and D. S. Russell. Arnold: London.

Hassler, R. (1938). Zur Pathologie der Paralysis agitans und des postenzephalitischen Parkinsonismus. Journal für Psychologie und Neurologie, 48, 387-476.

Henning, M., and Rubenson, A. (1970). Central hypotensive effect of 1-3,4-dihydroxyphenylalanine in the rat. Journal of Pharmacy and Pharmacology, 22, 553-560.

Hornykiewicz, O. (1966). Dopamine (3-hydroxytyramine) and brain function. Pharmacological Reviews, 18, 925-964.

Izumi, K., Inoue, N., Shirabe, T., Miyazaki, T., and Kuroiwa, Y. (1971). Failed levodopa therapy in striato-nigral degeneration. Lancet, 1, 1355.

Johnson, R. H., Lee, G. de J., Oppenheimer, D. R., and Spalding, J. M. K. (1966). Autonomic failure with orthostatic hypotension due to intermediolateral column degeneration. A report of two cases with autopsies. Quarterly Journal of Medicine, 35, 276-292.

Klaue, R. (1940). Parkinsonsche Krankheit (Paralysis agitans) und postencephalitischer Parkinsonismus. Archiv für Psychiatrie und Nervenkrankheiten, 111, 251-321.

Klawans, H., Jr., Ilahi, M. M., and Shenker, D. (1970). Theoretical implications of the use of L-dopa in Parkinsonism. Acta Neurologica Scandinavica, 46, 409-441.

Klawans, H. L., Jr., and Zeitlin, E. (1971). L-dopa in Parkinsonism associated with cerebellar dysfunction (probable olivopontocerebellar degeneration). Journal of Neurology, Neurosurgery, and Psychiatry, 34, 14-19.

McGeer, P. L., Boulding, J. E. ,Gibson, W. C., and Foulkes,
R. G (1961). Drug-induced extrapyramidal reactions. Journal of the American Medical Association, 177, 665-670.

McLennan, H., and York, D. H. (1967). The action of dopamine on neurones of the caudate nucleus. Journal of Physiology, 189, 393-402.

Mena, I., Court, J., Fuenzalida, S., Papavasiliou, P. S., and Cotzias, G. C. (1970). Modification of chronic manganese poisoning. Treatment with L-dopa or $5-\mathrm{OH}$ tryptophane. New England Journal of Medicine, 282, 5-10.

Nick, J., Contamin, F., Escourolle, R., Guillard, A., and Marcantoni, J.-P. (1967). Hypotension orthostatique idiopathique avec syndrome neurologique complexe à prédominance extra-pyramidale. Étude anatomo-clinique d'un cas. Revue Neurologique, 116, 213-227.

Poirier, L. J., and Sourkes, T. L. (1965). Influence of the substantia nigra on the catecholamine content of the striatum. Brain, 88, 181-192.

Schwarz, G. A. (1967). The orthostatic hypotension syndrome of Shy-Drager. Archives of Neurology, 16, 123-139.

Shy, G. M., and Drager, G. A. (1960). A neurological syndrome associated with orthostatic hypotension. Archives of Neurology, 2, 511-527.

Thomas, J. E., and Schirger, A. (1970). Idiopathic orthostatic hypotension. Archives of Neurology, 22, 289-293.

Watanabe, A. M., Chase, T. N., and Cardon, P. V. (1970). Effect of L-dopa alone and in combination with an extracerebral decarboxylase inhibitor on blood pressure and some cardiovascular reflexes. Clinical Pharmacology and Therapeutics, 11, 740-746.

Yahr, M. D., Duvoisin, R. C., Hoehn, M. M., Schear, M. J., and Barrett, R. E. (1968). L-dopa (L-3,4-dihydroxyphenylalanine). Its clinical effects in Parkinsonism. Transactions of the American Neurological Association, 93, 56-63. 